\title{
Pseudocoarctation of Aorta with Aneurysmal Dilatation with Acute Coronary Syndrome
}

\author{
Shankar Laudari ${ }^{*}$, Madhu Gupta ${ }^{2}$, Sachin Dhungel ${ }^{1}$, Rajesh Panjiyar ${ }^{2}$, Pawina Subedi ${ }^{3}$, Ghimire Bindesh ${ }^{3}$ and \\ Subramanyam $\mathrm{G}^{4}$ \\ ${ }^{1}$ Lecturer, Department of Cardiology, College of Medical Sciences-Teaching Hospital, Bharatpur, Nepal \\ ${ }^{2}$ DM Resident, Department of Cardiology, College of Medical Sciences-Teaching Hospital, Bharatpur, Nepal \\ ${ }^{3}$ Medical Officer, Department of Cardiology, College of Medical Sciences-Teaching Hospital, Bharatpur, Nepal \\ ${ }^{4}$ Professor, Department of Cardiology, College of Medical Sciences-Teaching Hospital, Bharatpur, Nepal
}

Received: 29 June,2017; Accepted: 06 July, 2017; Published: 14 July, 20177

*Corresponding author: Shankar Laudari, Lecturer, Department of Cardiology, College of Medical Sciences-Teaching Hospital, Bharatpur, Nepal, Tel: 977-9845112909; E-mail: Ishankar2@hotmail.com

\section{Non-structured Abstract}

Pseudocoarctation of the aorta is a very rare congenital anomaly characterized by kinking or buckling of the aorta at the level of the ligamentum arteriosum without a pressure gradient across the lesion [1]. Here, we report a case of pseudocoarctation of aorta with aortic aneurysmal dilatation presenting with acute coronary syndrome which is described as one of the rarest combination.

Keywords: Pseudocoarctation; Aneurysmal dilatation; Acute coronary syndrome

\section{Introduction}

Pseudocoarctation of aorta consists of an elongated arch with a kink at the level of the isthmus. It is thought to have been first described by Dotter, Steinberg, Souders and co-workers in 1951 [2,3]. Its exact etiology is not well known. One proposed embryologic cause is a failure of compression of the third through the seventh segments of the dorsal aortic roots and the fourth arch segment [1]. This condition does not cause obstruction or a gradient across the kinked segment; hence there is an absence of hemodynamic abnormalities.

The four major features of pseudocoartation of aorta are i) abnormal posterolateral chest radiograph ii) $<25 \mathrm{mmHg}$ pressure gradient across narrowed segment. iii) No evidence of increased collateral circulation or rib notching and iv) a diagnostic aortogram [4].

We describe a very interesting case of pseudocoarctation of aorta with aneurysmal dilatation who was referred to our center for management of acute myocardial infarction.

\section{Case Summary}

63 years male with past history of Type II DM and systemic hypertension developed acute chest pain 15 days back. Clinical evaluation, electrocardiography, echocardiography and myocardial enzymes were suggestive of acute ST elevation myocardial infarction. He was managed with medical treatment. His chest pain gradually subsided but had mild chest discomfort on exertion only. During hospital stay, he had few episodes of syncopal attack. So, he was referred to our center for further management.

On examination, patient was fair looking, average built and co-operative. BP on supine position was $110 / 70 \mathrm{mmHg}$ in both the upper limbs taken on brachial artery, and 104/60mmHg in bilateral lower limbs taken on dorsalis pedis artery. Standing BP was $100 / 60 \mathrm{~mm} \mathrm{Hg}$ taken at 2 and 5 mins interval. There was no evidence of postural hypotension. $\mathrm{ABI}$ is $>1$. Pulse was 76 beats/ min, regular, normal in volume and character, no radio-radial or radio-femoral delay and all the peripheral pulses were palpable. Jugular venous pressure was normal.

Electrocardiogram was suggestive of fully evolved anteroseptal wall myocardial infarction with lateral wall ischemia in sinus rhythm as shown in Figure 1.

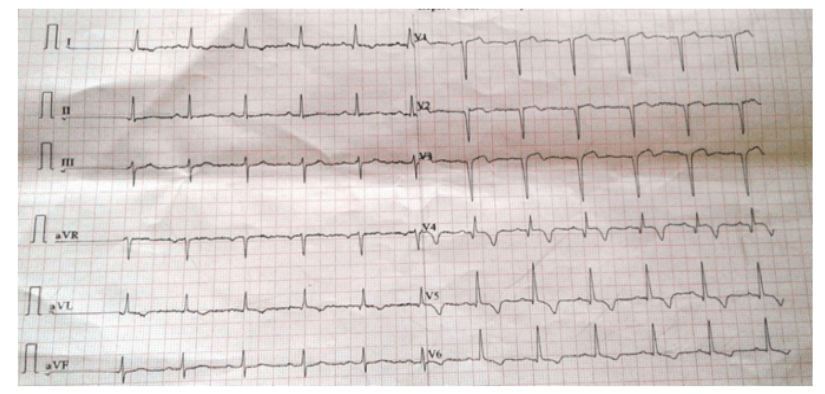

Figure 1: Electrocardiogram showing $Q$ waves with ST elevation in V1V4 with T inversion in I, AVL, V5, V6 in sinus rhythm

Chest X-ray was done which is suggestive of mild cardiomegaly with rotated film without ribs notching as shown below in Figure 2. 


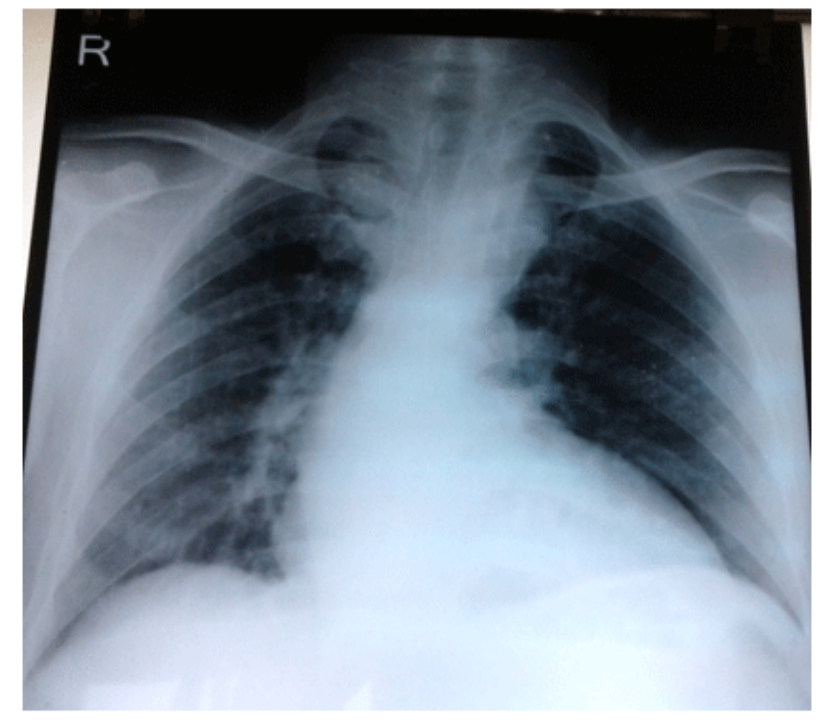

Figure 2: Chest radiography shows mildly rotated film with cardiomegaly without ribs notching

Routine hematological, renal, cardiac and other relevant biochemical investigations were done which are summarized in Table 1.
He had another episode of syncopal attack at rest on the bed. He was assessed with regular cardiac monitor for documentation of arrhythmias, regular BP recording, assessing for postural drop of blood pressure which were found to be normal. There was no feature of autonomic neuropathy and brain CT scan for head was normal.

Patient was taken for coronary angiography because of postinfarct angina and possible revascularization. Right femoral artery access was made and the guide wire along with Judkins catheter was introduced but to our surprise, the guide wire/catheter was advancing towards the neck on the left side and had resistance over there. Repeated manipulation of the catheter was done to pass into the ascending aorta for cannulation of sinus of valsalva but could not attempt. So, aortogram was done which revealed dilated descending aorta. Immediately, patient was taken for CT angiography which shows elongation, tortuosity with kinking of the distal aortic arch distal to left subclavian artery. Thoracic aorta is crossing to the right side of the spine and the arch of aorta is situated high in the mediastinum. No collaterals circulation or rib notching was noted, consistent with aortic pseudocoarctation as shown in Figure 3.

Patient was managed with low molecular weight heparin, antiplatelets, insulin and other medications for heart failure. His chest pain gradually subsided and he had no more syncopal attacks. Patient was discharged on sixth day of admission in stable condition.

Table 1: Show the different laboratory, cardiac and radiographic investigations

\begin{tabular}{|c|c|c|c|}
\hline Tests & Interpretation & Tests & Interpretation \\
\hline $\begin{array}{l}\text { Complete hemogram } \\
\text { Hgb-13gm\% } \\
\text { TLC-9850 } \\
\text { DLC-N68L28E1M1 Platelet- } \\
\text { 2.5lakhs } \\
\text { ESR- } 18 \mathrm{~mm} \text { /hour } \\
\text { Myocardial enzymes } \\
\text { Troponin I } \\
\text { CPK-MB- }\end{array}$ & $\begin{array}{l}\text { Positive } \\
\text { Positive }\end{array}$ & $\begin{array}{l}\text { Electrocardiogram- ST elevation with Q waves in V1-V4 with T } \\
\text { inversion in I,AVL,V5-V6 } \\
\text { Echocardiography- Akinetic apex with mildly dilated LV, Mild } \\
\text { AR, Mild MR Moderate LV systolic dysfunction (LVEF-35\%) } \\
\text { No significant gradient across the arch of aorta } \\
\text { Chest X-ray (Figure 2): Rotated film with mild cardiomegaly } \\
\text { Carotid Doppler- Bilateral enlarged carotid arteries. No stenosis. } \\
\text { CT scan Head- Normal study }\end{array}$ & $\begin{array}{c}\text { Fully evolved } \\
\text { anteroseptal wall } \\
\text { MI with lateral wall } \\
\text { ischemia } \\
\text { Ischemic heart } \\
\text { disease }\end{array}$ \\
\hline $\begin{array}{c}\text { Blood urea- } 23 \mathrm{mg} / \mathrm{dl} \\
\text { Serum creatinine } 1.0 \mathrm{mg} / \mathrm{dl}\end{array}$ & $\begin{array}{l}\text { Normal } \\
\text { Elevated }\end{array}$ & $\begin{array}{l}\text { Coronary angiography- attempted but wire could not be } \\
\text { negotiated across arch of aorta. }\end{array}$ & Abnormal \\
\hline $\begin{array}{l}\text { Serum uric acid-8mg/dl } \\
\text { Urine R/E- }\end{array}$ & Normal & $\begin{array}{l}\text { Aortogram- Reveals dilated descending aorta with obstruction at } \\
\text { arch of aorta. }\end{array}$ & \\
\hline 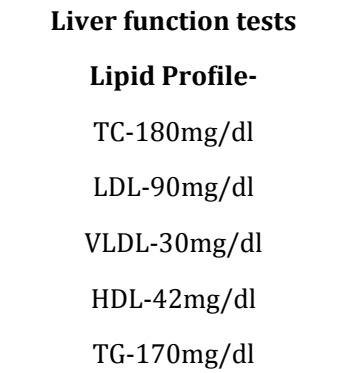 & Normal & $\begin{array}{l}\text { CT angiography- Showed elongation, tortuosity with kinking of } \\
\text { the distal aortic arch, distal to left subclavian artery. Thoracic } \\
\text { aorta crossing to the right side spine and the arch of aorta } \\
\text { situated high in the mediastinum. No collaterals circulation or } \\
\text { rib notching was noted, consisted with aortic pseudocoarctation. }\end{array}$ & $\begin{array}{l}\text { Pseudocoarctation of } \\
\text { aorta }\end{array}$ \\
\hline
\end{tabular}



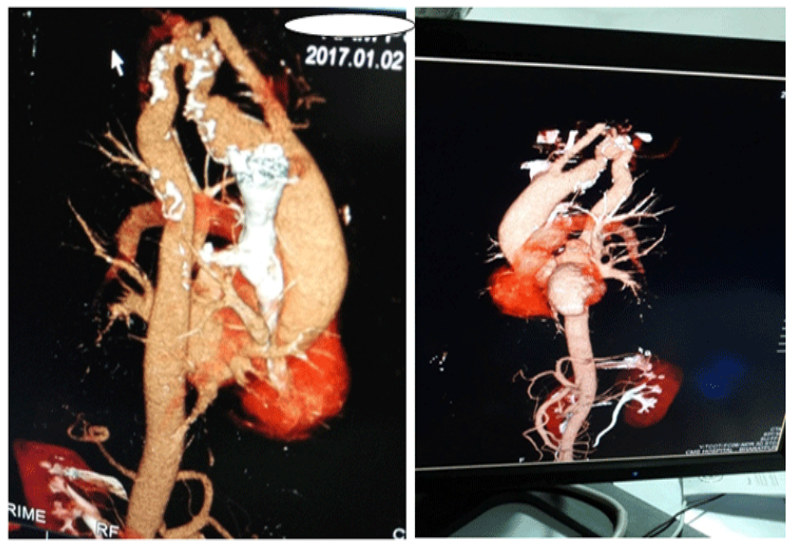

Figure 3: CT angiography shows elongated tortuous arch of aorta with kinking distal to left subclavian artery with no collaterals or ribs notching consistent with Pseudocoartation of aorta

\section{Discussion}

Our patient had elongated tortuous high cervical arch with pseudocoartation of aorta distal to left subclavian artery with aneurysmal dilatation without associated other cardiac anomalies. However, pseudocoarctation of aorta may be associated with other congenital cardiac anomalies including true coarctation of aorta, left cervical aortic arch, bicuspid aortic valve, mitral valve prolapse, ventricular septal defect, atrial septal defect and patent ductus arteriosus [5].

Majority of the patients with pseudocoarctation remain asymptomatic. They are diagnosed incidentally when being evaluated for some other medical conditions. However, they may present with dyspnoea, dysphagia, chest pain, back pain, palpitation and syncope [6]. Our patient presented with acute chest pain and syncope which are rare manifestations.

Echocardiography is a useful initial diagnostic tool to evaluate for associated congenital defects.

CT angiogram and MRI of the chest are important imaging modalities to evaluate the narrowed segment of the aorta and to rule out associated aortic aneurysm or aortic dissection.

Newer modalities such as flow sensitive cine imaging and three-dimensional imaging are valuable in assessing the gradient across the constricted area with high accuracy [5]. Cardiac catheterization is the gold standard for accurate measurement of the pressure gradient before endovascular or surgical intervention is planned or if diagnostic uncertainty exists.
Pseudocoarctation has been shown to be complicated by aneurysmal formation of the thoracic descending aorta leading to sudden aortic rupture or aortic dissection.

Symptomatic patients are managed conservatively. Indications for surgery include symptoms or radiological features of aortic dissection or impending aneurysmal rupture. Annual surveillance of thoracic aorta has been recommended for early diagnosis and intervention of aortic aneurysm [7].

\section{Conclusion}

Pseudocoarctation of aorta is a rare condition or abnormality and its occurrence with acute myocardial infarction is even rarer. There may be diagnostic and interventional challenges when presenting with myocardial infarction as in our patient. National and international case registries of such extremely rare medical conditions will help in understanding their natural history and can help direct the optimal management of these patients.

\section{Acknowledgment}

I would like to specially thank Dr. Pramod Chhetri and Mr. Indra Prasad Dumre and the entire cath. lab team for their immense help and co-operation.

\section{References}

1. Smyth PT, Edwards JE. Pseudocoarctation, kinking or buckling of the aorta. Circulation. 1972;46(5):1027-1032.

2. Son JS, Hong KB, Chung DC. Pseudocoarctation of the aorta associated with the anomalous origin of the left vertebral artery: a case report. Korean J Radiol. 2008;9(3):283-285. doi: 10.3348/kjr.2008.9.3.283

3. Joseph M, Leclerc Y, Hutchison SJ. Aortic pseudocoarctation causing refractory hypertension. N Engl J Med. 2002;346:784-785.

4. Gay WA Jr, Young WG Jr. Pseudocoarctation of the aorta. A reappraisal. J Thorac Cardiovasc Surg. 1969;58(5):739-745.

5. Singh S, Hakim FA, Sharma A, Roy RR, Panse PM, Chandrasekaran K, et al. Hypoplasia, Pseudocoarctation and Coarctation of the Aorta - a systematic review. Heart Lung Circ. 2015;24(2):110-118. doi: 10.1016/j.hlc.2014.08.006

6. Shindo S, Katsu M, Kojima A, Kobayashi M, Tada Y. Thoracic aortic aneurysm associated with pseudocoarctation of the aorta. Jpn J Thorac Cardiovasc Surg. 2002;50(12):520-522.

7. Amico A, Michaud JL, Baron O, Al Habash O, Despins P, Gaudin R, et al. Pseudocoarctation as cause of a refractory hypertension. J Cardiovasc Med 2007;8(4):289-290. 